This item was submitted to Loughborough's Research Repository by the author.

Items in Figshare are protected by copyright, with all rights reserved, unless otherwise indicated.

\title{
Is practical subject matter knowledge still important?: Examining the Siedentopian perspective on the role of content knowledge in physical education teacher education
}

\section{PLEASE CITE THE PUBLISHED VERSION}

http://dx.doi.org/10.1080/17408989.2016.1192592

\section{PUBLISHER}

(c) Taylor \& Francis

\section{VERSION}

AM (Accepted Manuscript)

\section{PUBLISHER STATEMENT}

This work is made available according to the conditions of the Creative Commons Attribution-NonCommercialNoDerivatives 4.0 International (CC BY-NC-ND 4.0) licence. Full details of this licence are available at: https://creativecommons.org/licenses/by-nc-nd/4.0/

\section{LICENCE}

CC BY-NC-ND 4.0

\section{REPOSITORY RECORD}

Herold, Frank, and Michael J. Waring. 2019. "Is Practical Subject Matter Knowledge Still Important?:

Examining the Siedentopian Perspective on the Role of Content Knowledge in Physical Education Teacher Education". figshare. https://hdl.handle.net/2134/21993. 


\section{Cover Page}

Title:

Is practical subject matter knowledge still important?: Examining the Siedentopian perspective on the role of content knowledge in physical education teacher education.

\section{Authors:}

Dr Frank Herold: University of Birmingham: f.a.herold@bham.ac.uk

Dr Michael Waring: Loughborough University: m.j.waring@ @lboro.ac.uk

\section{Corresponding author:}

Dr Frank Herold

School of Sport, Exercise and Rehabilitation Sciences

University of Birmingham

Edgbaston

B15 2TT

f.a.herold@bham.ac.uk

$0121 / 4148061$ 


\section{Is practical subject matter knowledge still important?: Examining the Siedentopian perspective on the role of content knowledge in physical education teacher education.}

\section{Introduction}

Physical education (PE) teachers play a critical role in facilitating pupils' learning and motivation to take part in PE (Iserbyt, Ward and Martens 2015; McEvoy, HeikinaroJohansson and MacPhail 2015; Moy, Renshaw and Davids, 2015; Nicaise et al. 2007). Graham (2008), somewhat simplistically, asserts that if teachers have comprehensive subject knowledge they can develop lessons that are interesting and enjoyable, therefore increasing the likelihood of motivating pupils to actively engage in PE lessons. However, pedagogical acting is a dynamic and complex undertaking and comprehensive subject knowledge alone is no guarantee that the teacher will be effective in facilitating successful learning experiences (Tinning 2002; Herold and Waring 2011). Moreover, learning to teach PE is a multidimensional enterprise, where knowledge and beliefs about teaching and learning are shaped over time through the processes of acculturation, professional and occupational socialisation, (Flory and McCaughtry 2014; Freak and Miller 2015; Stylianou et al. 2013).

Whilst pre-service teachers' (PSTs) beliefs are seen to underpin their pedagogical acting (Tannehill and McPhail 2014), other factors such as individual teacher attributes, and the context of the communities of practice $(\mathrm{CoP})$, within which PSTs' learning takes place are considered to be central to PSTs' development in Physical Education Teacher Education (PETE) (Chambers and Armour 2011, 2012; Gallo et al. 2015;). Moreover, subject knowledge itself is a complex construct and understanding the relative role that different dimensions of the subject knowledge base play in the development of PSTs are an important part of understanding the PETE process (Herold and Waring 2011; Ward 2009).

In his influential work on subject knowledge for teaching, Shulman (1987) identified seven dimension of the teacher knowledge base: content knowledge; pedagogical content knowledge (PCK); general pedagogical knowledge; curricular knowledge; knowledge of learners; knowledge of educational contexts and knowledge of educational ends. The focus of this paper is the dimension of knowledge Shulman (1987) has identified to be 'the base of all knowledge bases': content knowledge. In Shulman's (1987, p.8) conceptualisation content knowledge represents 'the specific subject matter knowledge, understanding and skills that are to be learned by school children'. Shulman (1987, p.9) recognises content knowledge to 
be a necessary foundation for effective teaching, identifying it to be 'the first source of the knowledge base' for teaching. Figure 1 provides a visual representation of Shulman's (1987) conceptualisation of the knowledge bases for teaching.

\section{Figure 1: Conceptualisation of Shulman's (1987) Knowledge bases for teaching}

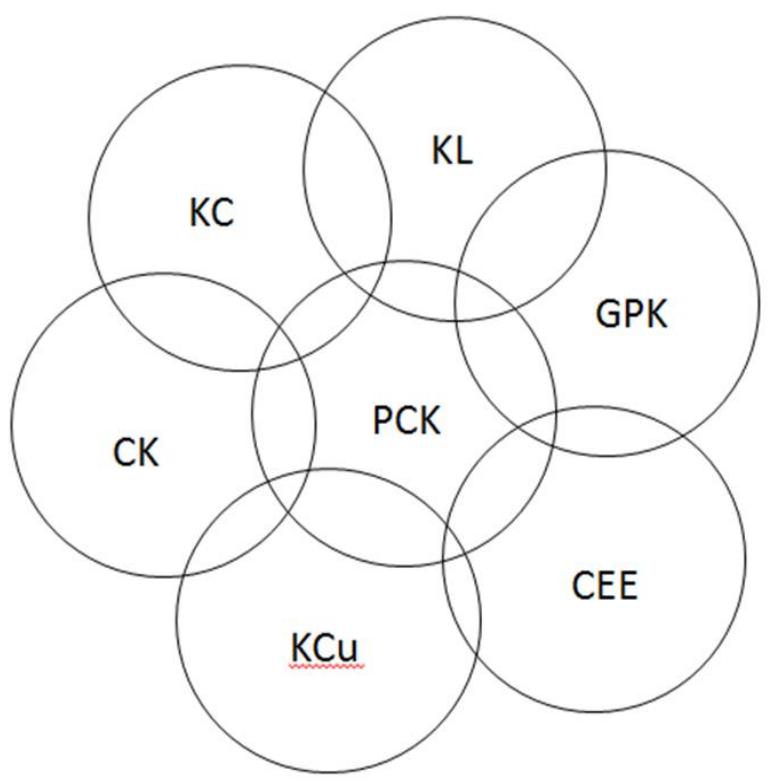

Content Knowledge

General Pedagogical

Knowledge

Knowledge of Learners

Knowledge of Curriculum

Knowledge of Contexts

Knowledge Educational

Ends

Pedagogical Content

Knowledge

Another important dimension of Shulman's (1987) model of subject knowledge for teaching is PCK. Shulman (1987 p.8) describes this as 'the special amalgam that is uniquely the province of teachers, their own special form of professional understanding. It represents the blending of content and pedagogy into an understanding of how particular topics, problems, or issues are organised for instruction.' In other words, it is this particular aspect of the teacher's subject knowledge which facilitates the learning process at the intersection between teacher and pupil, between what is to be learnt, and how this can be done, so that learning is accessible to the student.

The research underpinning this paper explored the development of subject knowledge in PSTs throughout their one year Post-Graduate PETE course in England. The paper focuses on PSTs perception of the role of content knowledge and its influence on their enacted knowledge for teaching (PCK). Concerns over the prioritisation of theory over practice in PETE, identifying content knowledge as an essential knowledge base for teaching effective PE have been raised since the late 1980s (Siedentop 2002/1989; Tinning 2002). Siedentop (2002/1989) asserts that without having at least reasonable knowledge of the skills, techniques, tactics and so forth of the activities we teach, there is very little hope that we will 
be able to teach these effectively. According to Kirk (2010a) these Siedentopian (2002/1989) concerns continue to be highly relevant for contemporary PETE.

I argued recently in Physical Education Futures (Kirk, 2010), that physical education teachers educated over the past 20 years, through no fault of their own, know substantially less about their subject matter - which is primarily games and sports and other socially valued practical physical activities - than earlier generations...The ongoing academicisation of PETE and consequent erosion of subject matter knowledge I suggest has been one reason among others for the resistance to change and perpetuation of a form of physical education that is concerned almost entirely with the teaching of de-contextualised sports techniques and what Inez Rovegno (1995) has called the molecularisation of physical education (Kirk 2010a, p. 30-31).

The position taken by Kirk (2010b) here implies a potential connection between a lack of (practical) subject matter knowledge and the de-contextualised teaching practices, frequently observed and criticised in English PE practice (Capel et al. 2011). However, the specific role that content knowledge has to play in this remains unclear. For instance, Siedentop (2002/1989) makes direct links between content knowledge and the enacted pedagogical knowledge by using the term PCK (Shulman, 1987); such an association has been supported by more recent studies into the relationship between content knowledge and PCK (Iserbyt, Ward and Martens 2015; Iserbyt, Ward and Li 2015; Ward et al. 2015). However, the nature of the impact of content knowledge on teaching and learning should not be considered a foregone conclusion. A focus on content and a prioritisation of content knowledge may lead to de-contextualised teaching which impede the development of more inclusive and pupil-centred approaches to PE and PETE (Enright et al., 2014; Capel 2007; Hayes et al. 2008; Velija et al. 2009). Hayes et al. (2008) contend that PSTs in PETE frequently equate content knowledge with subject knowledge and that the emphasis PSTs and their school-based mentors place on the development of such knowledge is at the expense of the development of more pupil-led pedagogies, such as Cooperative Learning (Goodyear and Casey 2015) and Sport Education (Farias, Hastie and Mesquita, 2015).

Despite such concerns it is also acknowledged that a lack of content knowledge can be a potential barrier to effective teaching (Sinelnikov et al. 2015) and to the development of PSTs teaching in PETE (Ayvazo et al. 2010; Griggs and Wheeler 2005; Herold and Waring 2009, 2011; Sloan 2007). The challenge for PETE is to develop PSTs who have a nuanced and balanced understanding of content knowledge as part of the knowledge base for teaching and its place in the context of pupils' learning which is located within a broad and balanced, relevant curricular context. 
This is in part being taken up and addressed by the subtle reinterpretation of content knowledge. For example, in more situated perspectives of learning, the definition of content knowledge has taken a more dynamic view of content knowledge, focusing on the coconstruction of content knowledge between teachers and pupils (Amade-Escot and O’Sullivan 2007; Rovegno and Gregg 2007). The development of 'content' here is a shared activity in which both pupils and teachers collaborate. However, to do so effectively the teacher needs content knowledge of as defined in the original conceptualisation by Shulman (1987).

Whilst the general (i.e. non-PETE) teacher education literature explicitly acknowledges the facilitative nature of content knowledge and in particular its link to PCK (Shulman 1987; Lowenberg Ball 2008; Ellis 2007), this is not so in the PETE literature where it remains conflicted and contested. As Kirk (2010b) speculates, it might just be the limitations of practical subject matter knowledge (content knowledge and PCK) which holds PETE students hostage to de-contextualised practices in teaching. It is the purpose of this study to consider the role of content knowledge and its impact on PSTs in PETE, thereby contributing to the evidence associated with this important, but albeit currently somewhat unfashionable area of research.

\section{Methodology}

\section{Research Focus and Theoretical Framework}

The focus of this study was the role that content knowledge and in particular practical aspects of content knowledge played in the development of PSTs during their PETE course. In its investigation of different aspects of the knowledge base for teaching this study utilised Shulman's (1987) theoretical framework for teacher knowledge. As one of the most influential frameworks utilised to research teacher knowledge in education (Lowenberg Ball 2008), Shulman's (1987) conceptualisation of teacher knowledge not only provides a framework for inquiry into the nature of teacher knowledge and its constituent factorsbut affords a degree of comparability of results, not only in PE, but also across the range of subject areas in teacher education.. 


\section{Participants and Setting}

The study reports on findings collected from 12 participants ( 6 female; 6 male; age: 22-26), who studied on a one year post-graduate PETE programme, delivered in partnership by a UK University and associated partnership schools. The programme of study was 36 weeks long and comprised a 24 week school-based and 12 week University-based learning. All participants held good honours graduate degrees from UK Universities (2.1 and higher) in sport-related subjects. University-based learning was delivered via a range of modes, including lectures, seminars, workshops, practical sessions and hybrid practical/theory workshops. University-based learning also included lectures, seminars and workshops on general education and pedagogy which was facilitated for the wider cohort of Initial Teacher Education (ITE) students.

School-based learning was anchored by the cycle of planning, teaching, reflection, feedback and evaluation across different contexts and age ranges in school. Key development tools included informal and formal feedback on teaching (most lessons), as well as weekly meetings with the dedicated mentor, providing a framework for joint reflection and action planning. PSTs' school-based learning was also supported through visits and observation of teaching by University tutors. Furthermore, collaborative learning was supported on the University Virtual Learning Environment (VLE), which provided a link between students and their University tutor, whilst the PSTs were on their school-based placement.

\section{The Researcher-Participant Relationship}

Within this study there were a number of ethical issues to consider as a consequence of the relationship between PSTs, school-based mentors and the primary researcher and the inter-connected involvement of each of them during the course of study. In the role as teacher educator on the course, the primary investigator/university tutor had a privileged status, potentially influencing the process of data collection, positively and/or negatively. For example, the researcher's knowledge of the participants and vice versa afforded both an insight beyond the research activities. As Chambers and Armour (2011) point out, the interconnectedness between researcher/university tutor, PSTs and mentors has an emotional dimension which also needs to be acknowledged throughout all stages of this study. The University ethical procedures were followed and approval of the study was granted. 


\section{Data Collection}

Adopting an interpretive methodology informed by constructivist grounded theory (Charmaz 2006, 2008), this study employed semi-structured interviews, lesson observations and post-lesson reflections conducted during three different stages of the PETE programme: early; mid-stage and end of the programme. These interviews explored PSTs' learning experiences and their development of knowledge for teaching. The interview schedule was flexible and designed to give the participants the opportunity to discuss their viewpoints, feelings and beliefs without being restricted (Flick 2007). To triangulate with the PSTs' selfreported perceptions on teaching, three lesson observations, including post-lesson reflections were also conducted with every PST throughout this study. All lessons selected for observation were agreed between the researcher and the PSTs. In line with the tenets of didactic analysis (Wallhead and O'Sullivan, 2007), lessons that might have been unduly influenced by behaviour management issues were avoided for the purpose of this research. The observations reported here are limited to practical field settings with no restriction on the type of activity that was included. The pursuit of learning across different domains was explored during post-lesson reflections. The observation strategy was based on an open framework of non-participant observation.

Detailed concurrent field notes and sign-posting questions were generated by the principal investigator / observer and then used during the facilitation of the post-lesson conference, which was recorded and transcribed verbatim. All data was transferred into the qualitative software tool NVIVO. In addition to this, weekly reflections on the University's VLE were used as an additional data. The data collection methods were selected for their alignment with those activities naturally occurring on the PETE course strengthening the ecological validity of the study (Denscombe, 2010).

\section{Data Analysis}

Coding was 'at the heart of the matter' (Waring, 2012, p. 301) and the fundamental means of developing the analysis of the data and its conceptual rendering in this study. A two stage procedure of coding, consisting of initial coding and focussed coding (Charmaz, 2006) was employed. As soon as the initial data had been gathered initial coding started. The purpose of initial coding is to break down the data, to look at the data critically and analytically, and to conceptualise what is happening in the data. The data was taken sentence 
by sentence and paragraph by paragraph in order to identify events, ideas and incidents which were compared and contrasted with each other to generate an emerging set of codes. To achieve more detailed conceptual and theoretical development, Charmaz (2006) advocates the use of analytical techniques, which entail the detailed examination of relationships between concepts, in order to unearth dimensions, contexts and conditions that correlate to the studied phenomenon. During the second phase of coding, the most significant and/or frequent initial codes that had been identified were used to generate more conceptual focused codes as part of the increasing process of conceptualisation and abstraction of the data. The focused codes were used to revisit and interrogate the data as part of a process of constant comparison.

Table 1 below demonstrates the process of analysis underlying the identification of different dimensions and relationships were established for the concept of content knowledge.

Table 1: Developing properties, dimensions and relationships: content knowledge Zeena: Interview 1

\begin{tabular}{|c|c|}
\hline Properties/Dimensions/ Relationships & Narrative \\
\hline $\mathrm{CK}$ is a consequence of sporting history & $\begin{array}{l}\text { My knowledge prior to the start of the course } \\
\text { was too specific to have been useful for a lot } \\
\text { of things. I knew about the things I had done } \\
\text { obviously and not really things like in the } \\
\text { areas I had not participated in. }\end{array}$ \\
\hline $\begin{array}{l}\text { CK has depth } \\
\text { Lack of CK adversely affects quality of } \\
\text { instruction/teaching }\end{array}$ & $\begin{array}{l}\text { I knew small bits about things but not } \\
\text { technical aspects of badminton... because } \\
\text { obviously you can't explain to someone why } \\
\text { they can't serve properly if you don't know } \\
\text { yourself. }\end{array}$ \\
\hline SK/CK is valued highly & $\begin{array}{l}\text { So I think it is quite important to have good } \\
\text { subject knowledge. }\end{array}$ \\
\hline $\begin{array}{l}\text { CK facilitates effective instruction } \\
\text { CK is transferrable? }\end{array}$ & $\begin{array}{l}\text { It can help a lot just breaking things down and } \\
\text { explaining what needs to be done and how it } \\
\text { feels in relation to maybe relating it to other } \\
\text { sports as well. }\end{array}$ \\
\hline
\end{tabular}




\begin{tabular}{|c|c|}
\hline $\begin{array}{l}\text { CK affects teaching confidence/self- } \\
\text { image/professional identity? }\end{array}$ & $\begin{array}{l}\text { For me if I am teaching something I feel quite } \\
\text { confident in, I set an example. }\end{array}$ \\
\hline $\begin{array}{l}\mathrm{CK} \text { affects teaching quality through ability } \\
\text { to react/adapt flexibly to lesson demands }\end{array}$ & $\begin{array}{l}\text { I can easily adapt what I'm doing if it is not } \\
\text { working with some people I can quickly } \\
\text { change and I have got quite a few backup } \\
\text { plans to what I am doing because I feel quite } \\
\text { confident in thinking if I put what I do across } \\
\text { if it doesn't work easily change round, }\end{array}$ \\
\hline $\begin{array}{l}\text { Limited context specific CK adversely } \\
\text { affects content selection } \\
\text { Limited CK adversely affects teaching } \\
\text { confidence }\end{array}$ & $\begin{array}{l}\text { whereas to me if it was something like } \\
\text { badminton for example I probably have a few } \\
\text { backup ideas but not as many so I wouldn't } \\
\text { feel as confident and I probably might not } \\
\text { come across as confident. }\end{array}$ \\
\hline
\end{tabular}

The example above highlights various dimensions and effects, that having or not having content knowledge had on PSTs. Specific themes relating to the concept were then checked against different cases, as well as other dimensions, such as the different stages of the training during which specific themes were prevalent. It demonstrated how having and not having content knowledge affected PSTs' in various ways. Through this, it underpinned the concept of 'valuing content knowledge' and various associated themes and their properties and dimensions. During the next stage, only data specifically associated with this concept was evaluated. The effects of relative levels of perceived content knowledge were investigated by revisiting corresponding categories during the process of focussed coding, with view to establishing the nature of these relationships at a more general level were evaluated. Charmaz (2006) denotes this as 'focussed coding'. This involved re-visiting the data and interpreting its meanings on a more abstract level. It also involved an examination of the relationships between different concepts. This was then conceptualised at a more abstract level as represented in the table below. 
Table 2: Valuing content knowledge: Themes, properties, dimensions

\begin{tabular}{|c|c|c|c|c|c|c|c|c|}
\hline 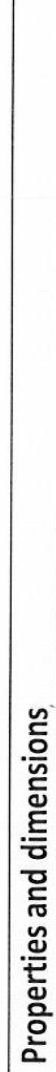 & 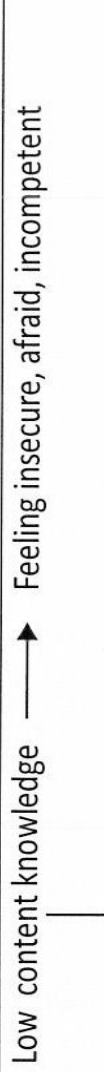 & 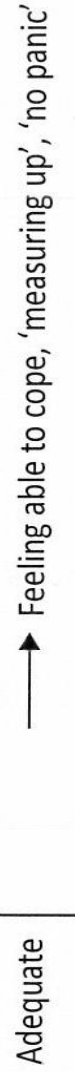 & 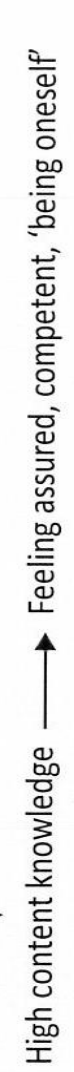 & 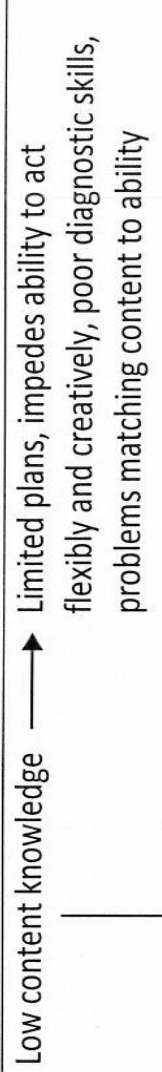 & 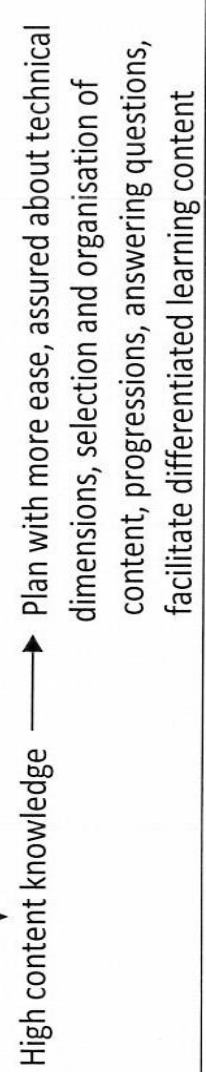 & 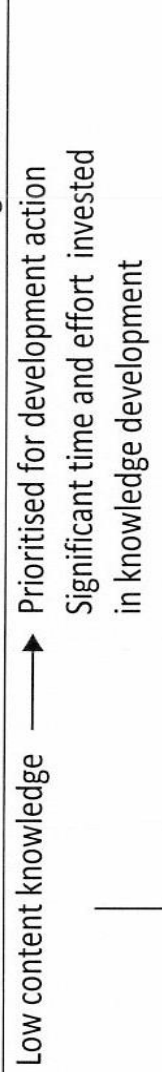 & 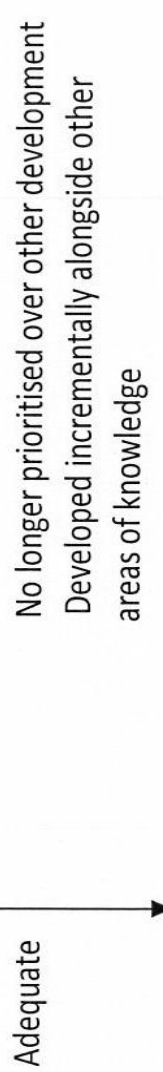 & 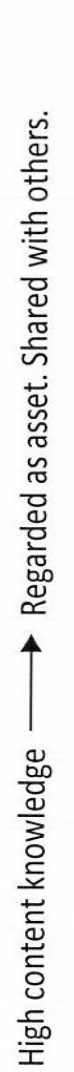 \\
\hline 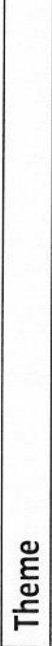 & 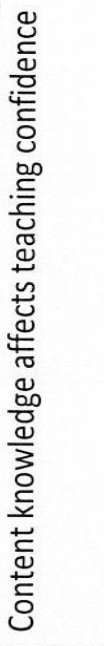 & & & 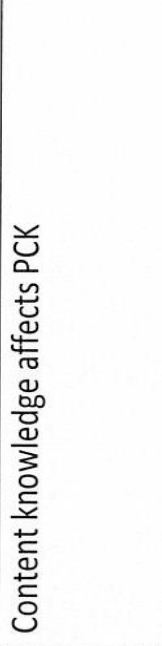 & & 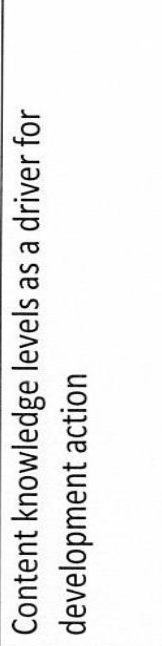 & & \\
\hline 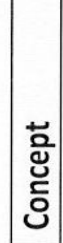 & 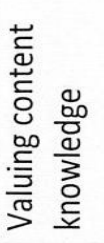 & & & & & & & \\
\hline
\end{tabular}


To refine the analysis at the more conceptual level, the properties and dimensions associated with them were again checked for consistency across cases and the different data sources that were utilised. Further visual representations that conceptualised salient effects that content knowledge had for the PSTs in this study were developed as part of this process. These are presented and discussed in the following section of this paper.

\section{Findings and Discussion}

\section{The perceived value of content knowledge: early stages of the training}

A consistent theme in this study was PSTs' perception that content knowledge had a facilitative effect on their teaching and they considered it to be a central aspect of their knowledge base. This was particularly evident during the early stages of their training, when content knowledge was valued highly by the PSTs in this study. In their reflections, many PSTs equated the term 'subject knowledge' frequently with the meaning of that aspect of knowledge termed by the literature as 'content knowledge'. Moreover, PSTs frequently conceptualised content knowledge to be context-specific to particular sports and activities and regarded the acquisition and possession of such knowledge to be a pre-requisite to become a competent and professional teacher of PE. In their narratives the PSTs constructed enabling notions of content knowledge and highlighted many positive effects that such knowledge had on their teaching. The notion of having sufficient content knowledge was further supported by the numerous adverse effects PSTs experienced in such activity areas where they perceived their content knowledge to be limited in range and breadth.

Consequently, they regarded the acquisition of such knowledge to be of central importance. Many PSTs expressed the desire to teach beyond the levels of basic knowledge and skills, reflecting Siedentopian (2002/1989) notions of going beyond teaching the fundamentals.

I think that good knowledge in the different activities is probably the most vital thing. I think it's unrealistic maybe at this stage that I have a great knowledge of all the complexities of all the different games, of all the you know aspects of gymnastics or all the different aspects of dance and to be good as a performer in all. But that would certainly be an aim of mine...I think right okay I need to do more gymnastics and more dance so that when I go into a lesson, I'm not just teaching the basics and I am able to tailor my skills to the needs of the class. (Matt, PST, Interview 1)

As PSTs evaluated their strengths and weaknesses in the context of the demands of the PE departmental curriculum in which they operated, they identified a range of knowledge 
limitations in relation to the specific practical activities they had to teach. Frequently, they categorised their knowledge in relation to their 'better' and 'weaker' subjects, further underlining their implicit view that such knowledge was inextricably linked to the context in which it was applied. Whilst the acquisition of breadth and depth of such knowledge was seen to be important, it was for its facilitative effects on pupil learning, rather than as an end in itself that PSTs considered this knowledge to be so important to their practice.

For a PE teacher, my perception of it would be to have knowledge of different activities, different sports, different physical activity, and then you can think in terms of understanding pupils and how backgrounds differ and match up the right things for them. So at the minute my take on it is when I teach in my better subjects that side of it makes it easier for me to teach better lessons. (Sophie, PST, Interview 1)

Whilst there were differences in these individual content knowledge profiles, most PSTs identified deficits in context specific content knowledge to have adverse effects on their teaching and development on the course. PSTs' individual knowledge profiles were shaped through earlier significant experiences that formed the basis of their knowledge at the start of the course. Individual content knowledge profiles were the consequence of a range of factors, such as personal sporting histories, school education and coaching experiences. In line with Siedentop's (2002/1989) assertions most PSTs also perceived that their undergraduate degrees had not prepared them sufficiently for the practical demands of teaching.

I've got a lot of criticisms of the Sports Science course. It was mostly theory like the psychology and physiology modules. It was really at a high level. Nothing I learnt in the physiology at University I'd really be able to introduce into key stage three or four and I've not been teaching a lot of A-level or BTEC at this moment in time (Emily, PST, Interview 1)

Considering Rovegno's (2008) concern over the need for undergraduate courses to contribute to a wide knowledge base in PE, many PSTs' reflections revealed significant concerns over the match of knowledge between their undergraduate studies and the requirements of their PETE course. Content knowledge deficits especially in practical activities were perceived to have a significant impact on cognitive and psychological dimensions of their learning and development. PSTs made many links between the importance of content knowledge, their teaching effectiveness and teaching confidence. These will be discussed in the following sections.

\section{The relationship of content knowledge and teaching confidence}


One of the most overt relationships that emerged from the data was that between content knowledge and teaching confidence. PSTs' narratives, especially during the early stages of the training, provided rich data to illuminate this relationship. The most immediate consequence of insufficient content knowledge was its negative effect on PSTs' confidence in their ability to teach good lessons.

Rugby, that's one of my fears, ultimate fears! I've never had any experience of teaching rugby. (Ellie, PST, Interview 1)

I suppose, I am nervous for a different reason. I am dreading basketball because I know virtually nothing about it... and I have got to teach some year nine's. I don't know what I am going to do. (Anna, PST, post-lesson reflection 1)

I didn't feel massively confident going into these badminton lessons, whereas if I am going into a football lesson then I'd feel that I could pretty much coach a football lesson without planning it... you need to come across as having this confidence so it looks like you do know what you are talking about. (Ben, PST, Interview 1)

The majority of these concerns were related to content knowledge deficits, i.e. those in specific practical activities, which formed the core of the respective PE curricula in their schools and therefore the day to day context in which they were teaching, reflecting immediacy concerns governing knowledge acquisition (Kinchin 2009). With relation to their self-image and professional identity, most PSTs stressed the importance of teaching confidence, if they were to perform effectively in their lessons. Conversely, the absence of such knowledge led to a range of negative responses and expressed itself in raised levels of anxiety about their ability to perform well in their teaching. This impact of low content knowledge on teaching confidence was consistent with all PSTs, even if different individuals were affected by it in different ways. PSTs gauged their existing knowledge within given specific contexts. Confidence was also related to how they perceived their level of content knowledge in relation to the specific teaching context. In this, however, PSTs made implicit distinctions between having adequate content knowledge and expert knowledge in specific activities.

I mean, obviously I don't think everyone has to be an expert, but I think it is important for a teacher to develop their own knowledge in sports, or different areas in sports, just so you can pass on as much as possible as you can to the pupils and give them a bigger opportunity. I do think that is important. (Anna, PST, Interview 1)

It's important to get the correct things across but I do not think that it is important to know everything about it. It is important that you know the key 
aspects for the level that you are going to teach and you know them well. (Kevin, PST, Interview 1)

Well, if you don't have enough (content) knowledge, you feel like you are failing them I suppose because you want them to do better and you are there to help them do that, but you can 't. (Zeena, PST, post-lesson reflection 1)

Concerns with teaching confidence were at their most pronounced when PSTs perceived their knowledge to be low in relation to the demands of the specific teaching situation. Pronounced negative effects on teaching confidence started to subside when PSTs felt that they had acquired an adequate level of context specific content. As levels of content knowledge rose to the levels that PSTs perceived to be adequate within the specific teaching context, the effects of content knowledge on teaching confidence started to level off. Figure 2 provides a visual representation of the relationship between content knowledge and teaching confidence that was identified to exist in this study.

Figure 2 Relative levels of content knowledge and its impact on teaching confidence

\section{Content knowledge and Confidence}

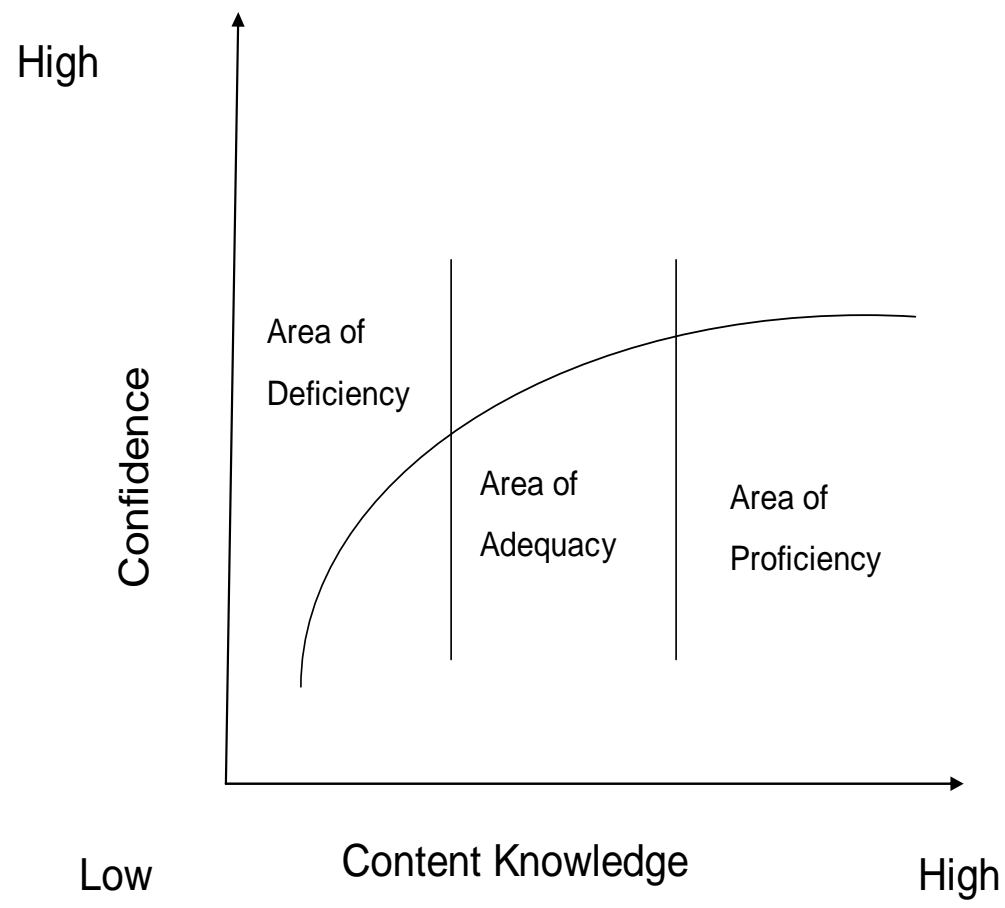


Anxieties about the perceived lack of adequate knowledge were heightened, when PSTs experienced a significant gap between their perceived existing content knowledge and the content knowledge they felt would be required in any given specific context. This happened for instance when they were teaching in areas where their own knowledge was perceived to be, or identified by others as low. It could also be affected by teaching the older year groups, when PSTs feared that a higher level of content knowledge would be required. This was based on the perception that older pupils had a potentially more advanced ability profile. In turn, these pupils were expected to have raised expectations of the level of the lesson content they would experience.

Basketball, I still struggle with the in-depth knowledge of that. I know the basics, and that just about works for my year 7s, but I'm feeling a lot less confident when I'm teaching the older ones... I'm planning more for these lessons, because I constantly worry that I don't know enough about it. It's the lot really, rules, umpiring, tactics... There are some really good players in my year 10 boys group and getting them to improve on what they do... I find that really hard (Ollie, PST, Interview 1)

Yeah. In subjects that I'm not that strong with I feel it's easier to teach the younger pupils than the older ones. Just because the older ones obviously if they're a specialist in the subject, will have a better knowledge of it than me and I feel that the Key Stage 3 are maybe a bit more naïve and a bit more understanding if you get it wrong. (Sophie, PST, Interview 1)

Whilst all PSTs felt the need to improve their content knowledge, there were differences between individuals in terms of the extent to which they experienced these pressures. In this, there was a tendency for those with the widest ranging content knowledge deficits to experience more significant negative effects. More limited profiles contributed to experiencing pressure and stress and these PSTs reported more difficulties caused through lack of such knowledge, potentially supporting Siedentop's (2002/1989) earlier and Kirk's (2010a,b) more recent assertions about the enabling nature of content knowledge.

The strategies they applied to prioritising which aspects of content knowledge to tackle were significantly influenced by the demands of their immediate teaching requirements. The highest priority was accorded to those aspects of content knowledge in which the gap between perceived immediate requirement and actual competence was greatest. Existing content knowledge was perceived to be a form of useful capital by the PSTs that could be employed within its specific contexts. Here, urgent investment in activities leading to knowledge acquisition needed to be undertaken. Figure 3 represents the value ascribed to 
content knowledge in context and its relationship to these implicit development strategies in a graphical format.

Figure 3: The relationship between actual and required content knowledge and its impact on development prioritisation strategies

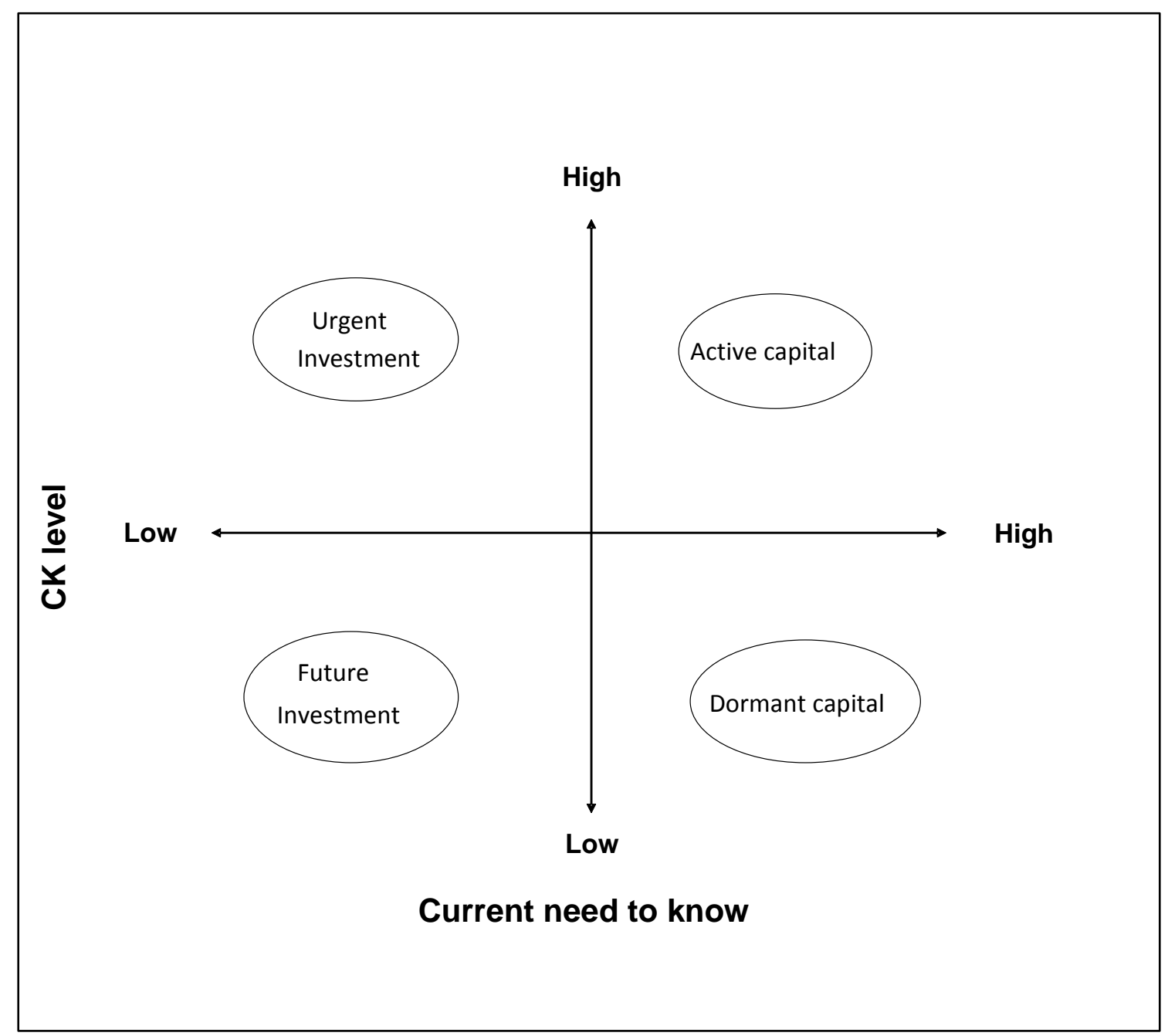

PSTs addressed content knowledge weaknesses through increased planning, gathering information from a wide range of sources, including books, the internet, other PSTs on their course, or their mentors. In this process, PSTs experienced challenges both with their lack of content knowledge, as well as with the complexity of the process of planning, teaching and evaluating itself. The need for diligent planning, combined with the complexity of issues related to teaching and evaluation, constituted a time intensive activity on the PGCE course. 
Pressure on time to address these issues continued to be a concern for PSTs in these early stages of the training.

This week has been a whole different story. From observer and passive teacher to leader I have been up all hours planning, planning and planning. It's just a shame about the actual delivery! During the lesson I'm so busy thinking about what I have to consider, assessment, non-participants, etc. that struggling to find time to breathe and enjoy it. (Naomi, PST, early-stage VLE reflection)

In these pressurised circumstances PSTs valued knowledge that was relevant to their immediate teaching needs. The time spent alleviating perceived content knowledge deficits increased the pressure on PSTs to manage in less time the other range of activities associated with their school-based learning, including the development of more sophisticated pedagogies (Capel et al., 2011). PSTs strategies for content knowledge development were framed by the notion that 'at least' adequate content knowledge was necessary to facilitate teaching effectively.

\section{The facilitative role of content knowledge: later stages of the training}

As their training progressed, PSTs increasingly recognised that content knowledge by itself was insufficient, if they wanted to teach engaging lessons.

Whilst PSTs continued to attribute importance to content knowledge, they appreciated that it was the interplay of various aspects of knowledge and personal competencies that was responsible for the sum of outcomes that represented their teaching. In addition to content knowledge, they recognised aspects of PCK, but also elements of curricular knowledge and general pedagogical knowledge to be important for their teaching success. Whilst PSTs developed a more sophisticated understanding of the relationship between teacher, content and pupils which influenced the outcomes of their teaching (Armour, 2011), they continued to value content knowledge to be an important part of their teaching, recognising in particular a wide range of connections between content knowledge and PCK forming the constituent factors of practical subject matter knowledge. Both aspects of knowledge were frequently bound together by the activity specific context in which they were taught. For instance, in order to be able to organise learning effectively and stretching pupils over the course of a whole module, PSTs felt that they needed to have a sufficiently extensive range of content to pick from. 
Yeah like with the dance I had to make a real conscious effort to go and find out ways to extend them, because the differentiation was there for the first couple of weeks, but as soon as they had achieved our extension activities then you have got another seven weeks that you have got to keep them, and of course more weeks the further on that they get in school, you have got to find more challenges in activities for them. You do have to work really hard in terms of trying to push your own subject knowledge in order to keep them achieving. Sometimes you just think, where am I going to get that from? (Robert, PST, Interview 2)

In this, PSTs perceived limitations in content knowledge to be one of the factors that affected their ability to select suitable content for extension tasks and teaching progressions to address learning challenges flexibly as they arose. In line with Siedentop's (2002/1989) notions about the facilitative role of content knowledge, PSTs felt that lack of content knowledge made it harder for them to facilitate suitable learning for pupils at the advanced end of the ability spectrum and experienced frustration when their lack of content knowledge presented a barrier to achieving this.

Then, if within the lesson my more able pupils are achieving really well in the more difficult tasks that's when I struggle to further them more, to differentiate more than I'd already planned to do...If I've got to think on my feet that's when it's harder. (Ellie, PST, Interview 3)

The perception that good content knowledge would allow them to act more flexibly and creatively in response to pupils' needs as they arose during lessons, was seen to be one of its key assets during the later stages of the training.

With the stuff I don't know that well, I sometimes struggle, because I am not really sure where to go next and how to effect the change for those pupils. And that has an effect with the teaching because it is a lot slower in pace, rather than if I know what I am going for it is smoother, I can go round rather than having to go that way. It means that I can move how I need to from what I see, like deviate from that plan with more confidence. (Tim, PST, Interview 3)

Whilst content knowledge would not guarantee good lessons, it would improve the chances of it happening. In line with Kirk's (2010a) assertion that practical subject matter knowledge (content knowledge and PCK) may facilitate less fragmented approaches to teaching, PSTs felt that it helped them to escape from the rigidity of the lesson plan and respond more effectively to pupils' needs. It was PSTs' perception that the facilitative effects of in-depth content knowledge allowed them to act more creatively in response to the requirements of teaching situations, indicating a positive relationship between content knowledge and PCK (Iserbyt, Ward and Li 2015; Sinelnikov et al. 2015). The close link 
between these two dimensions of knowledge was a consistent theme throughout this investigation, which also endured during the later stages of the training. In the main, content knowledge was valued not as an aim in itself, but for its facilitative value.

When I was doing netball lessons I was a lot more creative and a bit more daring and willing to try a bit crazy things just because I knew if this went wrong I would be able to on the spot change it there and then just from the experience that I've got and the understanding of it whereas in football... when I was teaching football at SE1 I was a bit more reluctant to go off my lesson plan, do you know what I mean? (Zeena, PST, Interview 3)

Throughout the investigation, lack of content knowledge was seen as a constraining factor in the enactment of PCK, even if the extent of this diminished over the duration of the course. For instance, the need to facilitate differentiated learning was seen to be difficult, particularly in activity areas where they deemed their content knowledge to be low. The lesson plan, whilst considered to be helpful, was not sufficient to cater for the situations when what was planned did not work out in the actual lesson.

Whilst notions of more advanced concepts of teaching PE, such as concepts associated with pupil-centred teaching styles, games-based teaching and assessment were developing in the thinking of all PSTs, realising those strategies in practice continued to be contextualised through the activities prescribed through the multiactivity curriculum operated by most PE departments for core PE. Content knowledge deficits could be mediated through good support at school, for example from an expert mentor. However, PSTs were aware that ultimately they would be responsible for their own teaching.

Content knowledge deficits and lack of intimate knowledge of pupils were frequently identified as joint challenges as PSTs tried to plan and teach their lessons, further highlighting the interconnection between content knowledge and other bases of subject knowledge. Restrictions in content knowledge also made it harder to recognise the conceptual and motor learning problems that the pupils experienced, a phenomenon that has also been recognised by previous and more recent research (Rovegno 1993; McCaughtry and Rovegno 2003; Sloan 2007; Herold and Waring 2011; Ward et al. 2015).

With netball, I know what my outcome should be. However, if they're not achieving it, I'll modify it, and if they're achieving it first time I'll increase the difficulty. But with tennis, I find it hard to achieve that expected outcome, I don't 
always really know what they should be able to achieve, if that makes sense.

(Emily, PST, Interview 3)

Despite their improved knowledge profiles across the range of knowledge bases, PSTs continued to report negative impacts of limited content knowledge on PCK. Although these were now less severe in nature, they were nevertheless still of importance to PSTs. With increased experience and understanding of the teaching process, the perceived impact of content knowledge deficits had, however, undergone a subtle, but important change. Whilst content knowledge limitations during the earlier stages of the training had given rise to personal concerns such as those about teaching confidence, PSTs' were less concerned with the consequences of limited content knowledge on themselves, and more about the potential effects it had on their ability to facilitate high quality learning experiences for their pupils.

In recognising the facilitative qualities that in-depth content knowledge could have on their enacted teaching (PCK), PSTs acknowledged that the absence of such knowledge affected their ability to respond effectively to their pupils' learning needs. Content knowledge deficits therefore impeded some of the transformative processes that were needed to enact PCK in the form of creative, flexible and pedagogical decision making.

\section{Conclusions}

In line with Siedentop's (2002/1989) critique of the academicisation of PETE, this study confirmed the important role of content knowledge as part of a rounded and balanced subject knowledge for PSTs. Confirming theoretical deliberations on the role of content knowledge (Kirk, 2010a, b), as well as recent primary research (Iserbyt, Ward and Martens 2015; Ward et al. 2015; Sinelnikov et al. 2015), PSTs in this study recognised a connection between content knowledge and various dimensions of their teaching, especially PCK. Such perceptions are consistent with Siedentopian (2002/1989) notions of content knowledge and its facilitative effects on learning and teaching.

Content knowledge deficits were perceived to have multiple adverse effects on PSTs' practice, as well as their development on their PETE course. Throughout this study content knowledge had context specific dimensions, which were pre-dominantly activity referenced. Considering the immediacy of knowledge requirements, especially during the early stages of their training, PSTs valued and prioritised knowledge that was closely aligned with the curricular activities of their schools. 
The notion of 'adequacy' of knowledge indicated the required level of content knowledge which PSTs deemed necessary if they were to perform their teaching with confidence. Throughout the course of their training PSTs' perceptions of the value they accorded to content knowledge also underwent changes, leading to a more balanced view of content knowledge in relation to other knowledge bases. Even so, content knowledge continued to be an important, facilitative and valued part of their knowledge base. Whilst such knowledge by itself does not guarantee good teaching, the debate about the wider role of content knowledge needs to be re-visited. This also needs to be done in the context of any statutory curricular expectations. A simplistic view of content knowledge is not being advocated in this paper, nor is its prioritisation over other bases of knowledge. Content knowledge by itself is not the solution to improving the quality of PSTs' teaching, it is but one dimension of a well-rounded subject knowledge profile. In the current climate of academic priorities and funding limitations at UK universities developing range and depth of content knowledge represents a challenge for all of those involved in PETE.

\section{References}

Amade-Escot, C. and O'Sullivan, M. (2007) Research on content in physical education: theoretical perspectives and current debates, Physical Education and Sport Pedagogy, 12 (3), $185-204$.

Armour, K. M. (Ed.) (2011) Sport Pedagogy: An introduction for Teaching and Coaching. London: Pearson.

Ayvazo, S., Ward, P., Stuhr, P. (2010) Teaching and Assessing Content Knowledge in Preservice Physical Education, Journal of Physical Education, Recreation and Dance, 81 (4), 51-60.

Capel, S. (2007) Moving beyond physical education subject knowledge to develop knowledgeable teachers of the subject, Curriculum Journal, 18 (4), 493-507.

Capel, S., Hayes S, Katene W., and Velija, P. (2011) The interaction of factors which influence secondary student physical education teachers' knowledge and development as teachers, European Physical Education Review, 17(2), 183-201.

Chambers, F. and Armour, K. (2011) Do as we do and not as we say: teacher educators supporting student teachers to learn on teaching practice, Sport, Education and Society, 16 (4), 527-544. 
Chambers, F. and Armour, K. (2012) School-university partnerships and physical education teacher education student: A fruitful division of labour?", European Physical Education Review, 18 (2), 159-181.

Charmaz, K. (2006) Constructing Grounded Theory: A practical guide through qualitative analysis. London: Sage.

Charmaz, K. (2008) Shifting the Grounds: Constructivist Grounded Theory Methods. In Morse, M., Stern, P.N., Corbin, J. M., Charmaz, K. (2008) Developing Grounded Theory: the Second Generation. London: Sage.

Denscombe M. (2010) The Good Research Guide (4th Ed). Maidenhead: Open University Press.

Ellis, V. (2007) Taking subject knowledge seriously: from professional knowledge recipes to complex conceptualizations of teacher development, Curriculum Journal, 18(4), 447- 462. Farias, C., Hastie, P. A., and Mesquita, I. (2015) Towards a more equitable and inclusive learning environment in Sport Education: results of an action research-based intervention. Sport, Education and Society, (ahead-of-print), 1-17.

Flick U. (2007) Managing Quality in Qualitative Research. London: Sage.

Flory, S. B., and McCaughtry, N. (2014) The Influences of Pre-Professional Socialization on Early Career Physical Educators. Journal of Teaching in Physical Education, 33(1).

Gallo, A. M., Sheehy, D., Bohler, H., \& Richardson, K. (2015) "We've Got Next”-PETE Faculty's Role in Promoting Professional Learning. Journal of Physical Education, Recreation and Dance, 86(2), 29-33.

Freak, A., and Miller, J. (2015) Magnifying pre-service generalist teachers' perceptions of preparedness to teach primary school physical education, Physical Education and Sport Pedagogy, DOI: 10.1080/17408989.2015.1112775.

Goodyear, V. A., and Casey, A. (2015) Innovation with change: Developing a community of practice to help teachers move beyond the 'honeymoon' of pedagogical renovation. Physical Education and Sport Pedagogy, 20(2), 186-203.

Graham, G. (2008) Teaching Children Physical Education - Becoming a Master Teacher. London: Routledge. Griggs, G. and Wheeler, K. (2005) Mind the Gap!: The implications for undergraduates studying sports-related degrees and gaining places on PE PGCE courses, British Journal of Teaching Physical Education, 36 (4), 6-8.

Herold, F. and Waring, M. (2009) Pre-service physical education teachers' perceptions of subject knowledge: Augmenting learning to teach, European Physical Education Review, $5(3), 337-364$. 
Herold, F. and Waring, M. (2011) So much to learn, so little time...: pre-service physical education teachers' interpretations and development of subject knowledge as they learn to teach, Evaluation and Research in Education, 24(1), 61-77.

Iserbyt, P. Ward, P. and Martens, J. (2015) The influence of content knowledge on teaching and learning in Traditional and Sport Education contexts: an exploratory study, Physical Education and Sport Pedagogy, DOI:10.1080/17408989.2015.1050662

Iserbyt, P. Ward, P. and Li, W. (2015) Effects of improved content knowledge on pedagogical content knowledge and student performance in physical education, Physical Education and Sport Pedagogy, DOI: 10.1080/17408989.2015.1095868

Kinchin G. (2009) From entry to completion: An examination of secondary physical education student teachers expectations of initial teacher education across one PGCE course, British Educational Research Association Conference, University of Manchester, 1-4 September.

Kirk, D. (2010a) Why research matters: Current status and future trends in physical education pedagogy, Movimento 16 (2): 11-43.

Kirk, D. (2010b) Physical Education Futures. London: Routledge.

Loewenberg Ball, D., Thames, M.H., and Phelps, G. (2008) Content Knowledge for Teaching: What Makes It Special?, Journal of Teacher Education, 59 (5), 389-407. McEvoy, E., Heikinaro-Johansson, P., \& MacPhail, A. (2015) Physical education teacher educators' views regarding the purpose (s) of school physical education. Sport, Education and Society, 1-13. McCaughtry, N. and Rovegno, I. (2003) Development of pedagogical content knowledge: moving away from blaming students to predicting skillfulness, recognising motor development and understanding emotion, Journal of Teaching in Physical Education, 22(4), 355-368.

Moy, B., Renshaw, I. and Davids, K. (2015) The impact of nonlinear pedagogy on physical education teacher education students ' intrinsic motivation, Physical Education and Sport Pedagogy, DOI: 10.1080/17408989.2015.1072506.

Nicaise, V., Bois, J., Fairclough, S. Amorose, A. and Cogenns, G. (2007) Girls and boys perceptions of physical education teachers' feedback. Effects on performance and psychological responses, Journal of Sports Sciences, 25 (6), 915-926.

Rovegno, I. (1993) The development of curricular knowledge: a case of problematic pedagogical content knowledge during advanced knowledge acquisition, Research quarterly for exercise and sport, 64(1), 56-68. 
Rovegno, I. and Gregg, E. (2007) Using folk dance and geography to teach interdisciplinary, multi-cultural subject matter: a school-based study, Physical Education and Sport Pedagogy, 12(3), 205-223.

Rovegno, I. (2008) Learning and Instruction in Social, Cultural Environments: Promising Research Agendas, Quest, 60, 84-104.

Shulman, L. S. (1987) Knowledge and Teaching: Foundation of the new reform, Harvard Educational Review, 57(1), 1-22.

Siedentop, D. (2002/1989) Content knowledge for physical education, Journal of Teaching in Physical Education, 21(4), 368-377.

Sloan, S. (2007) An investigation into the perceived level of personal subject knowledge and competence of a group of pre-service physical education teachers towards the teaching of secondary school gymnastics, European Physical Education Review, 13(1), 57-80.

Stylianou, M., Kulinna, P. H., Cothran, D., \& Kwon, J. Y. (2013) Physical education teachers' metaphors of teaching and learning. Journal of Teaching in Physical Education, 32 (1), 22-45.

Tannehill, D., and MacPhail. A. (2014) What examining teaching metaphors tells us about PSTs' developing beliefs about teaching and learning, Physical Education and Sport Pedagogy, 19 (2), 149-163, doi:10.1080/17408989.2012.732056

Tinning, R. (2002) Engaging Siedentopian Perspectives on Content Knowledge in Physical Education, Journal of Teaching in Physical Education, 21 (4), 378-391.

Velija, P., Capel, S., Katene, W. and Hayes, S. (2009) Does knowing stuff like PSHE and citizenship make me a better teacher?: Student teachers in the teacher training figuration, European Physical Education Review, 14 (3), 389-405.

Wallhead, T. and O'Sullivan, M. (2007.) A didactic analysis of content development during the peer teaching tasks of a Sport Education season, Physical Education and Sport Pedagogy, $12(3), 225-243$.

Waring, M. (2012) Grounded theory. In: Arthur, J., Waring, M. Coe, R. and Hedges, L. (Eds.). 2012. Research Methods and Methodologies in Education. London: Sage. Ward, P. 2009. "Content Matters: Knowledge that Alters Teaching." In Historic Traditions and Future Directions of Research on Teaching and Teacher Education in Physical Education, edited by L. Housner, M. Metzler, P. Schempp, and T. Templin, 345-356. Morgantown, WV: Fitness Information Technology. 
Ward, P., Kim, I., Ko, B., \& Li, W. (2015) Effects of improving teachers' content knowledge on teaching and student learning in physical education. Research Quarterly for Exercise and Sport, 86(2), 130-139.

Sinelnikov, O. A., Kim, I., Ward, P., Curtner-Smith, M., and Li, W. (2015) Changing beginning teachers' content knowledge and its effects on student learning. Physical Education and Sport Pedagogy, (ahead-of-print), 1-16. 